\title{
Montane refugia predict population genetic structure in the Large-blotched Ensatina salamander
}

\author{
THOMAS J. DEVITT,$* \dagger$ SUSAN E. CAMERON DEVITT, + BRADFORD D. HOLLINGSWORTH, $\S$ \\ JIMMY A. MCGUIRE* and CRAIG MORITZ* \\ *Department of Integrative Biology and Museum of Vertebrate Zoology, University of California, 3101 Valley Life Sciences \\ Building, Berkeley, CA 94720-3160, USA, "Department of Wildlife Ecology and Conservation, University of Florida, 316 \\ Newins-Ziegler Hall, PO Box 110430, Gainesville, FL 32611-0430, USA, §Department of Herpetology, San Diego \\ Natural History Museum, PO Box 121390, San Diego, CA 92112, USA
}

\begin{abstract}
Understanding the biotic consequences of Pleistocene range shifts and fragmentation remains a fundamental goal in historical biogeography and evolutionary biology. Here, we combine species distribution models (SDM) from the present and two late Quaternary time periods with multilocus genetic data (mitochondrial DNA and microsatellites) to evaluate the effect of climate-induced habitat shifts on population genetic structure in the Large-blotched Ensatina (Ensatina eschscholtzii klauberi), a plethodontid salamander endemic to middle and high-elevation conifer forest in the Transverse and Peninsular Ranges of southern California and northern Baja California. A composite SDM representing the range through time predicts two disjunct refugia, one in southern California encompassing the core of the species range and the other in the Sierra San Pedro Mártir of northern Baja California at the southern limit of the species range. Based on our spatial model, we would expect a pattern of high connectivity among populations within the northern refugium and, conversely, a pattern of isolation due to long-term persistence of the Sierra San Pedro Mártir population. Our genetic results are consistent with these predictions based on the hypothetical refugia in that (i) historical measures of population connectivity among stable areas are correlated with gene flow estimates; and (ii) there is strong geographical structure between separate refugia. These results provide evidence for the role of recent climatic change in shaping patterns of population persistence and connectivity within the Transverse and Peninsular Ranges, an evolutionary hotspot.
\end{abstract}

Keywords: California Floristic Province, Ensatina, Holocene, last glacial maximum, paleomodelling, Pleistocene, refugia

Received 10 September 2011; revision received 20 November 2012; accepted 26 November 2012

\section{Introduction}

Global climate fluctuations have resulted in major shifts in species' distributions, leaving genetic signatures that may be used to test the relative role of historical climate change in divergence and speciation in different envi-

Correspondence: Thomas J. Devitt, Fax: 352-846-0253;

E-mail: tommydevitt@gmail.com

†Present address: Florida Museum of Natural History, University of Florida, Dickinson Hall, Museum Road \& Newell Drive, PO Box 117800, Gainesville, FL 32611-7800, USA ronments around the globe (Hewitt 1996, 2000, 2004; Lessa et al. 2003; D'Horta et al. 2011). Integrating paleodistribution models with genetic data has proven to be a particularly powerful approach for untangling the effects of late Quaternary climatic oscillations on the genetic structure of organisms (Carstens \& Richards 2007; Carnaval et al. 2009; Bell et al. 2010). Paleodistribution modelling can predict the location and extent of stable refugia - areas where a species is predicted to have persisted throughout climatic fluctuations and associated habitat shifts — thereby forming spatially explicit hypotheses about historical demography that 
can be tested quantitatively using molecular data (Carstens \& Richards 2007; Knowles et al. 2007; Carnaval et al. 2009). If populations experienced long-term isolation in separate refugia during climatic oscillations, we would expect to see a pattern of strong genetic divergence among refugia (Carnaval et al. 2009; Bell et al. 2010; Lawson 2010). Conversely, if cyclical fluctuations have permitted recurrent population connectivity, gene flow may have masked any earlier periods of divergence in allopatry and genetic divergence among populations may be low (Green et al. 1996; Nice \& Shapiro 2001; Schoville \& Roderick 2009).

Montane species are particularly useful for evaluating the genetic consequences of climatic oscillations because they are often restricted to a narrow range of environmental conditions (Bell et al. 2010; Lawson 2010; Rovito 2010). As a result, many montane-adapted species exist as isolated populations under today's relatively warm climate, but possibly experienced range expansions during cooler glacial cycles allowing for increased population connectivity and gene flow (Hewitt 2004; Wiens 2004). The Transverse and Peninsular Ranges of southwestern California and northern Baja California are home to a remarkably high concentration of endemic lineages (Stein et al. 2000; Rissler et al. 2006; Vandergast et al. 2008). This endemism is thought to reflect a combination of several evolutionary drivers of diversification, including steep environmental gradients, species interactions and recent geologic and/or climatic change (Calsbeek et al. 2003; Lapointe \& Rissler 2005; Davis et al. 2007). Specifically testing how these processes have driven divergence in this 'evolutionary hotspot' (Davis et al. 2007; Vandergast et al. 2008) is key to understanding their relative contribution in shaping biodiversity patterns, as well as for effective conservation prioritization aimed at preserving evolutionary processes (Crandall et al. 2000; Moritz 2002).

Here, we test for the effect of recent (late Quaternary) climate change in the Large-blotched Ensatina salamander (Ensatina eschscholtzii klauberi), a direct-developing (i.e. no aquatic larval stage), lungless, plethodontid salamander endemic to conifer forests in the eastern Transverse and Peninsular Ranges of southern California and northern Baja California (Mahrdt et al. 1998; Stebbins 2003; Heim et al. 2005). These forests have experienced major altitudinal shifts during the late Quaternary (Minnich 2007a), moving downslope by at least $900 \mathrm{~m}$ when temperatures were $4{ }^{\circ} \mathrm{C}-5{ }^{\circ} \mathrm{C}$ cooler than today during the late Pleistocene c. 24-58 ka (Anderson et al. 2002). The transition from the Pleistocene to the modern Holocene climate around 10 ka marked a major shift to a warmer climate, with a period of an increased precipitation during the mid-Holocene (5.0-3.5 ka) in California (Minnich 2007a). Because terrestrial salamanders are intimately linked to the environment physiologically (Feder 1983), they respond to even minute changes in microclimate or community succession (Davic \& Welsh 2004) and as such, are excellent indicators of environmental change. Using species distribution models (SDM) for the present and potential distributions at two different time periods in the past representing climatic extremes during the late Quaternary (21 ka and $6 \mathrm{ka}$ ), we make predictions about the distribution of genetic diversity and population connectivity of this montane specialist, and test those predictions using multilocus genetic data. Specifically, we test whether current population isolates have been connected and experienced gene flow during the recent past when conditions were presumably more favourable for amphibians (i.e. wetter). This study extends previous phylogeographic work in the southern California Floristic Province by (i) identifying environmentally stabile areas that may have served as refugia for montane species in the eastern Transverse and Peninsular Ranges during Quaternary climatic oscillations; and (ii) providing evidence that recent climate-induced habitat shifts have shaped patterns of population connectivity and gene flow in this evolutionary hotspot.

\section{Methods}

\section{Study area}

The Large-blotched Ensatina is patchily distributed in the eastern Transverse and Peninsular Ranges of southern California and northern Baja California. In the eastwest oriented Transverse Ranges, E. e. klauberi inhabits only the San Bernardino Mountains (Fig. 1A). In the northwest-southeast trending Peninsular Ranges, the species inhabits (from roughly north to south) the San Jacinto and nearby Santa Rosa Mountains, Volcan, Hot Springs, and Palomar Mountain, the nearly continuous Cuyamaca and Laguna Mountains and in the Sierra de Juárez and Sierra San Pedro Mártir of Baja California (Fig. 1A-B). Climate throughout most of the range is Mediterranean (winter rain and dry summers), although the Sierra de Juárez and Sierra San Pedro Mártir receive summer thundershowers from the North American monsoon when tropical moisture is present (Minnich 1983). Suitable habitat in the study area consists of scattered stands of conifer and mixed-conifer forest mostly at middle and high elevations (c. 1200-1900 m elevation). Mountain basins $<1200 \mathrm{~m}$ elevation are characterized by oak woodlands and chaparral lacking conifer species (Minnich 2007b), where E. e. klauberi is replaced by its more common congener E. e. eschscholtzii throughout much of its range. An unusual exception to the typical habitat is found at sea level in Baja California near the city of San Quintín, where an isolated 

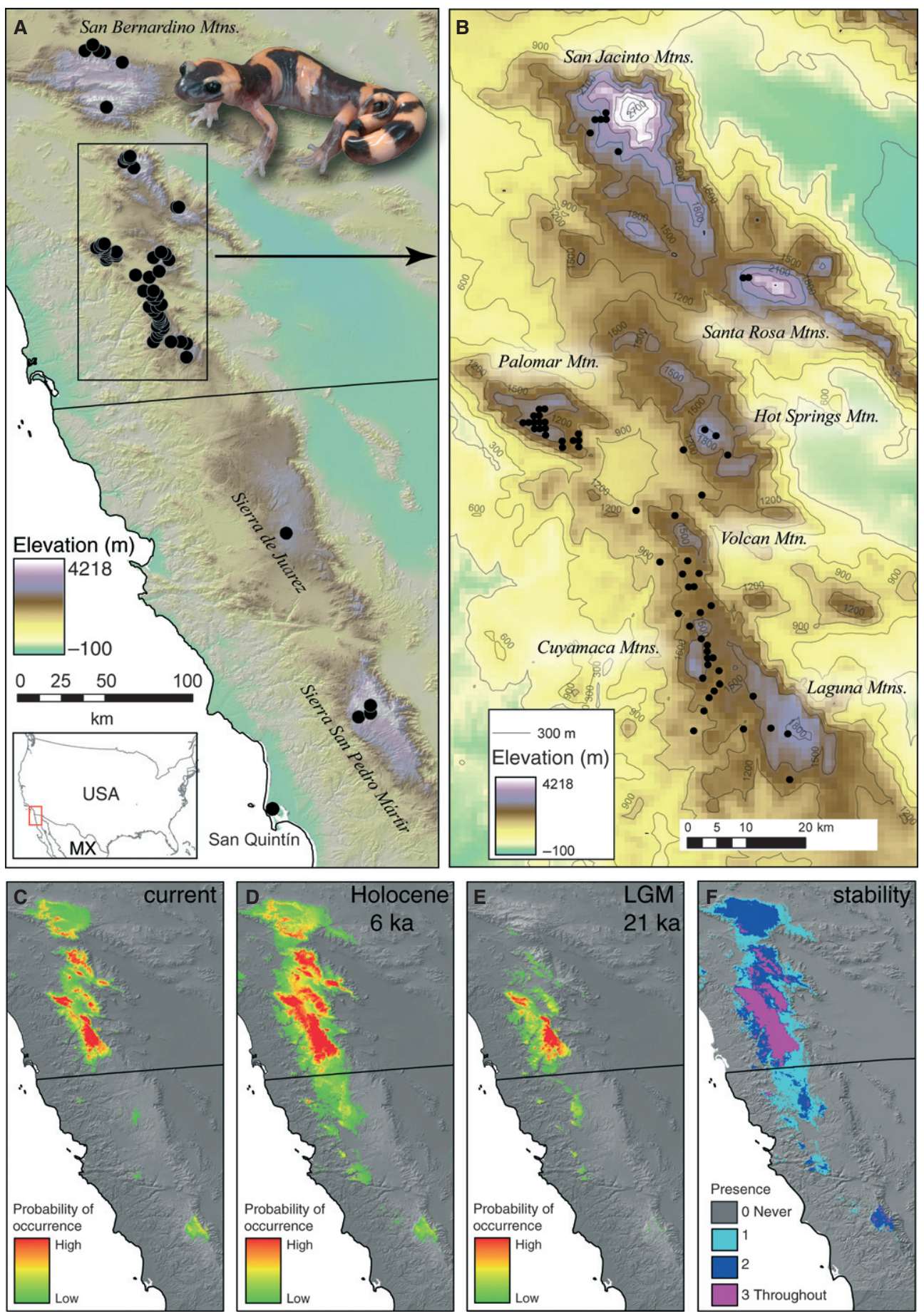

Fig. 1 Distribution of the Large-blotched Ensatina (Ensatina eschscholtzii klauberi) in southern California and northern Baja California showing unique localities used in distribution modelling (A-B). Species distribution models at present (C), Holocene (HOL; D), last glacial maximum (LGM; E), and a stability map representing the intersection of the models over all three time periods (F). Stability values range from 0 (never present) to 3 (present during all three time periods).

population of E. e. klauberi inhabits a treeless, rocky area surrounded by maritime desert scrub.

In California, moist, north-facing slopes are dominated by white fir (Abies concolor), incense cedar (Calocedrus decurrens), and bigcone Douglas fir (Pseudotsuga macrocar$p a)$, while south-facing slopes and valley floors are characterized by more open stands of Jeffrey pine ( $P$. jeffreyi) (Minnich 2007b). In Baja California, Jeffrey pine forests 
cover basins along the crest of the Sierra de Juárez and middle elevations $(1400-1800 \mathrm{~m})$ of the Sierra San Pedro Mártir, while upper elevations of the Sierra San Pedro Mártir are characterized by mixed-conifer forests dominated by Jeffrey pine, white fir, sugar pine (Pinus lambertiana), and incense cedar (Minnich 2007b).

\section{Species distribution modelling}

Species distribution models were constructed using 91 unique locality records from collections at the Museum of Vertebrate Zoology (MVZ), San Diego Natural History Museum (SDNHM) and Universidad Autónoma de Baja California, Ensenada (UABC). The majority of locality records $(n=83)$ are from California, with relatively few records $(n=8)$ in Baja California. It is important to note this difference, because areas with a larger number of records may have a greater influence on the SDM. However, based on our experience as well as previous workers' field efforts in Baja California (Mahrdt et al. 1998; Heim et al. 2005), population density differences on either side of the USA-Mexico border appear to be real and are not merely an artefact of sampling bias in favour of California. To investigate whether the greater number of records in California unduly influenced the model, we subsampled the $n=83$ California records to one locality record per $10 \mathrm{~km}^{2}$ grid cell, resulting in a total of $n=23$ records, and projected the species' distribution for current conditions using both the original and the subsampled data sets. In addition to modeling the species' distribution under current conditions, we also projected the distribution at two different time periods in the recent past: (i) the last glacial maximum (LGM) a cooler, wetter period (relative to the present) c. $21 \mathrm{ka}$; and (ii) the Holocene (HOL) a warmer, wetter period relative to present conditions c. $6 \mathrm{ka}$. Current climatic conditions were estimated from the global climate database WorldClim (Hijmans et al. 2005). Paleoclimate conditions were generated from statistically downscaled estimates from the ECHAM3 model available from WorldClim (see worldclim.org for details of the downscaling procedure). We used the ECHAM3 model because it has been demonstrated to perform well in paleoclimate reconstruction (Braconnot et al. 2007). Distribution models were constructed using the maximum entropy algorithm implemented in MAXENT (Phillips et al. 2006). We identified correlated climatic variables using a Pearson's correlation test and removed those that were significantly correlated following Johnson et al. (2002). This resulted in 10 variables: annual mean temperature, temperature seasonality (coefficient of variation across months), mean temperature of the wettest quarter, mean temperature of driest quarter, mean temperature of warmest quarter, annual precipitation, precipitation seasonality, precipitation of driest quarter, precipitation of warmest quarter and precipitation of coldest quarter. The model prediction was restricted to southern California (Imperial, Kern, Los Angeles, Orange, Riverside, San Bernardino, San Diego and Ventura counties) and northern Baja California (Ensenada, Mexicali, Tecate and Tijuana municipalities). Five thousand background points were generated from the study region, including the Transverse Ranges, Peninsular Ranges, and the coast, removing those points that were within $1 \mathrm{~km}$ of an actual occurrence record. Restricting background to the 'area accessible' is recommended to reduce error in model parameterization, validation, and comparison (Barve et al. 2011).

Data were randomly partitioned into training (75\%) and testing $(25 \%)$ data sets and bootstrapped for 100 replicate runs to evaluate model performance. We compared area under the curve (AUC), Kappa and the true skill statistic (TSS) to evaluate model performance, as well as to identify an appropriate threshold for presence and absence (Fielding \& Bell 1997; Allouche et al. 2006). We selected the threshold that maximized Kappa as recommended by Freeman \& Moisen (2008), which allowed us to convert the probabilistic MAXENT results to a binary map indicating species presence and absence. We visually inspected the MAXENT clamping output to determine the amount of extrapolation (model variables in the prediction surface being outside their training range). Clamping values range from 0 (no clamping) to 1 (all variables outside their training range). The resulting presence-absence maps for the three time periods were summed to estimate range stability through time. Stability values ranged from 0 (never present) to 3 (present during all three time periods). Areas with a stability value of 3 were classified as potential refugia. All GIS calculations and analyses were performed in ArcGIS 9 (ESRI, Redlands, CA, USA).

\section{Genetic sampling}

A total of 68 individuals from 14 sites were sampled, representing nearly all known populations ( $n=1-14$ individuals per sample; Table S1, Supporting information). Each individual was genotyped at 10 microsatellite loci, and all but three were also sequenced for one mitochondrial gene. GPS coordinates, with error estimates $(<10 \mathrm{~m})$, were taken at the point of capture for each individual. Individuals from protected areas and localities for which voucher specimens already exist were sampled nonlethally by removing a small piece of the tail tip and released; specimens from new localities were euthanized and preserved as voucher specimens in the MVZ, University of California, Berkeley, and UABC, Ensenada, Baja California, México, following UC Berkeley IACUC protocols. Tissue samples collected in the field (tail tips) were stored in $95 \%$ ethanol or propylene glycol and later frozen at $-80{ }^{\circ} \mathrm{C}$ in the lab. 


\section{Molecular methods}

DNA was extracted from tissues (liver or tail tip) using Qiagen DNeasy tissue kits following the manufacturer's protocol (Qiagen, Valencia, CA, USA). An $\sim 800$ base pair fragment of mitochondrial DNA (mtDNA) comprised of the ND4 gene and flanking tRNAs (His, Ser, Leu) was amplified via the polymerase chain reaction (PCR) using the primers ND4 and LEU (Arévalo et al. 1994). PCRs consisted of 35 cycles of $94{ }^{\circ} \mathrm{C}$ for $1 \mathrm{~min}$., $48{ }^{\circ} \mathrm{C}$ for $2 \mathrm{~min}$., and $72{ }^{\circ} \mathrm{C}$ for $3 \mathrm{~min}$. PCR products were purified using sodium acetate. Purified templates were sequenced using dye-labelled dideoxy terminator cycle sequencing on an ABI 3730 automated DNA sequencer. DNA sequences were edited and aligned using GENEIOUS v4.8.5 (Biomatters). Microsatellite loci were amplified and genotyped following Devitt et al. (2009) on an ABI 3730 DNA analyzer (Applied Biosystems, Inc.). Alleles were scored by hand using GENEMAPPER v.4.0 (ABI). MSATALLELE v.1.0 (Alberto 2009) was used to visualize the scoring of alleles and check for genotyping errors.

\section{Microsatellite descriptive statistics}

Allelic richness $(A)$ and private allelic richness $\left(A_{\mathrm{P}}\right)$ were calculated for samples with a minimum of three individuals using rarefaction to account for differences in sample size among sites using HP-RARE (Kalinowski 2005). We calculated the following: (i) observed heterozygosity $\left(H_{\mathrm{O}}\right)$; (ii) expected heterozygosity $\left(H_{\mathrm{E}}\right)$ (Levene 1949); (iii) exact tests of Hardy-Weinberg equilibrium (HWE; Haldane 1954; Guo \& Thompson 1992; Weir 1996); (iv) null allele frequencies (Dempster et al. 1977); (v) $F_{\text {IS }}$ (Robertson \& Hill 1984); and (vi) exact G tests of population differentiation based on allelic frequencies (this being more powerful than tests of genotypic differentiation when samples are small compared to the level of variability; Goudet et al. 1996) using GENEPOP v.4.0.10 (Raymond \& Rousset 1995; Rousset 2008). Significance was assessed using Markov chain Monte Carlo (MCMC) simulation (Guo \& Thompson 1992) with default values for the Markov chain (100 batches with 1000 iterations per batch and 1000 dememorization steps), followed by a sequential goodness-of-fit test to correct for multiple comparisons implemented in $\mathrm{SGoF}+$ (Carvajal-Rodriguez \& de Uña-Alvarez 2011).

\section{Inferring population genetic structure}

We used Bayesian clustering models to estimate the number of populations $(K)$ and individual population memberships using STRUCTURE v.2.3.2 (Pritchard et al. 2000; Falush et al. 2003, 2007) and Geneland v.4.0.2 (Guillot et al. 2005a,b, 2008; Guillot \& Santos 2009). For both programs, we explored values of $K$ from one to a maximum of 15. Null alleles (sample group-specific double missing genotypes) were coded as missing data for STRUCTURE analyses, whereas in GENELAND they were explicitly taken into account using the 'filter null alleles' option (Guillot et al. 2008). We explored all possible combinations of the allele frequency model (correlated/uncorrelated) for both programmes and both ancestry models in STRUCTURE (admixture/no-admixture; GENELAND assumes no-admixture). Our preferred model assumes correlated allele frequencies and no-admixture because (i) allele frequencies are most likely similar in different populations due to migration or shared ancestry (Guillot 2008); and (ii) a model assuming no-admixture is more realistic given the low dispersal capability of Ensatina (tens of metres; Staub et al. 1995; Stebbins 1954) relative to the area sampled, along with the spatially clustered distribution of individuals. We used the default setting of $\lambda=1$ for analyses using the correlated allele frequencies model. In STRUCTURE, we incorporated sample group information as a prior (Hubisz et al. 2009). GENELAND analyses were performed with the spatial model that incorporates geographical coordinates of sampled individuals (treating spatial coordinates as certain). Ten runs were conducted for each value of $K$ in STRUCTURE, with each run consisting of 100000 sweeps after a burn-in of 50000 sweeps. We chose the best $K$ by examining both the log probability of the data $\left(\ln \operatorname{Pr}\left(X^{\prime} K\right)\right)$ and the $\Delta K$ statistic following Evanno et al. (2005). GENELAND analyses consisted of 10 independent runs for each of the possible modelling combinations, each consisting of 100000 iterations with a thinning of 100 after a burn-in of 50000 iterations. MCMC convergence was assessed by comparing the number of populations across replicate runs, with the mean posterior density used as a criterion to choose the best run under a given set of model conditions.

\section{Testing the effects of climate change on gene flow and population connectivity}

Our hypothesis is that climate-induced habitat shifts have shaped patterns of population persistence and connectivity and thus population genetic structure. To test this hypothesis, we examined whether our stability surface (Fig. 1F) could predict observed genetic differentiation between pairs of populations. Our approach follows McRae (2006) and McRae \& Beier (2007) in using circuit theory to model gene flow across a spatially heterogeneous landscape. The isolation by resistance (IBR) model (McRae 2006; McRae \& Beier 2007; McRae et al. 2008) implemented in CIRCUITSCAPE v.3.5.7 (McRae \& Shah 2009) calculates 'resistance' distances among sampled populations using raster habitat data as 
input, in this case, the stability surface (hypothetical refugia) from our SDM. The stability surface was used as a conductance grid, that is, higher conductance values were assigned to grid cells that allow greater movement, and lower conductance values to cells representing greater resistance to movement. Conductance values for each grid cell were calculated by subtracting the per-cell stability value $(0,1,2$, or 3$)$ from the maximum stability value (3).

To evaluate the performance of the IBR model as a predictor of observed differentiation between sampled populations, we compared it to a null model of isolation by distance (IBD; Wright 1943) using the regression method of Rousset (1997). Rousset's (1997) method involves a regression of $F_{\mathrm{ST}} /\left(1-F_{\mathrm{ST}}\right)$ estimates for pairs of groups against geographical distance for populations in linear habitats (one-dimensional IBD) or the logarithm of distance for populations in planar habitats (twodimensional IBD). This regression provides an estimate of the neighbourhood size (the product of population density and mean square dispersal rate; Rousset 1997). Deciding when habitat is one- or two-dimensional is not always obvious in practice (Rousset 1997). At a broad scale, this species' distribution is linear, suggesting a onedimensional model is more appropriate, but at a local scale (i.e. within a neighbourhood), habitat is two-dimensional. We calculated regressions for both $1 \mathrm{D}$ and 2D models. Eleven populations were identified based on combined results from GENELAND and exact $\mathrm{G}$ tests of population differentiation (see results). Because null alleles may result in the overestimation of $F_{\mathrm{ST}}$ when populations are significantly differentiated (Chapuis \& Estoup 2007), we estimated $F_{\mathrm{ST}}$ with and without null alleles using Weir's (1996) estimator implemented in FREENA (Chapuis \& Estoup 2007) with 10000 bootstrap replicates to assess significance. Genetic and geographical distances were calculated in GENEPOP 4.1.3 (Rousset 2008) with microsatellites and mtDNA combined into a single data set. We calculated $F_{\mathrm{ST}} /\left(1-F_{\mathrm{ST}}\right)$ (Rousset 1997), as well as a minor variant of this estimator analogous to Rousset's (2000) individual-based statistic, introduced in version 4.1 of GENEPOP (Rousset 2012). The original $F_{\mathrm{ST}} /\left(1-F_{\mathrm{ST}}\right)$ method uses per-pair estimates of within-deme gene diversity (the denominator of this equation), while the newer variant uses a single estimate for all pairwise statistics (i.e. a common denominator for all comparisons; Rousset 2012). The latter, in principle, should perform better for small per-group samples (Rousset 2012). Statistical significance of the correlation was assessed using a Mantel test (Mantel 1967) with 10000 randomizations generated by permuting samples between geographical locations implemented in the program IsOLATION BY DisTANCE Web Service v.3.22 (Jensen et al. 2005). The slope and intercept were calculated using reduced major axis
(RMA) regression, the preferred method over ordinary least squares regression when the independent variable is measured with error (Hellberg 1994). $R^{2}$ values were used to assess model fit following McRae (2006) and McRae \& Beier (2007).

\section{mtDNA phylogeography}

We conducted a phylogenetic analysis of mtDNA in MRBAYES v3.1.2 (Huelsenbeck \& Ronquist 2001; Ronquist \& Huelsenbeck 2003), modified to incorporate compound Dirichlet branch length priors (Rannala et al. 2012; Zhang et al. 2012). Because a single model of nucleotide substitution may not provide the best fit to the data (Nylander et al. 2004; Brandley et al. 2005), we partitioned our data into subsets and ran a mixedmodel analysis. We used the Bayesian Information Criterion (BIC) implemented in the software PARTITIONFINDER (Lanfear et al. 2012) to choose the optimal partitioning scheme and best-fit nucleotide substitution model for each partition. HKY+I was used for first codon positions and tRNAs, F81 for second codon positions and $\mathrm{GTR}+\Gamma$ for third codon positions. The tree was rooted using Ensatina eschscholtzii croceater, the closest relative of E. e. klauberi (Moritz et al. 1992; Jackman \& Wake 1994; Kuchta et al. 2009). Four independent analyses were run for $10^{7}$ generations, each using random starting trees and a compound gamma-Dirichlet prior on tree length (Rannala et al. 2012; Zhang et al. 2012). In each analysis, four Markov chains (using default heating values) were sampled every 500 generations. Stationarity was evaluated by examining trace files and effective sample size (ESS) values from MCMC runs in TRACER v1.5 (Rambaut \& Drummond 2007). Trees sampled prior to reaching stationarity were discarded as burn-in and the remainder used to construct a $50 \%$ majority rule consensus tree. Posterior probability values were used to assess phylogenetic support (Huelsenbeck \& Ronquist 2001); clades with values $>95 \%$ were considered to be well supported.

\section{Results}

\section{Predicted range dynamics}

There was no difference in goodness of fit or the prediction surface between the entire data set and the subsampled data set (Fig. S1, Supporting information); therefore, we used all unique locality records to construct the final distribution models. Results were consistent across the 100 bootstrap replicates (Figs S2-S4, Supporting information), and we present the best fitting model here. Our SDM for current climatic conditions performed well over the majority of the range. The 
maximum Kappa value was 0.956 for the equal sensitivity and specificity threshold (threshold value $=0.112$ ). TSS value for this threshold was 0.983. Statistics for other thresholds are provided in Table S2 (Supporting information). Values $>0.112$ were considered to be present and values $<0.112$ were considered absent. Visual inspection of clamping revealed no clamping (clamping value 0) within the species' range (Fig. S5, Supporting information). Response curves for each climatic variable are provided in the Supporting information (Fig. S6). Sierra de Juárez and San Quintín did not fall within the predicted range (Fig. 1C), although an area very near the Sierra de Juárez population was predicted. Populations at the northern and southern distributional limits of the species' range in the San Bernardino Mountains and Sierra San Pedro Mártir, respectively, showed a lower probability of occurrence relative to the remainder of the range. There was some minor overprediction of the model into the San Gabriel Mountains to the west of the San Bernardino Mountains where the species does not occur (not shown). The ECHAM3 HOL climate model predicts temperatures approximately $1{ }^{\circ} \mathrm{C}$ warmer throughout the range and precipitation 0-5\% lower in Baja California and 10-20\% higher in California. During the LGM, ECHAM3 predicts temperatures approximately $1.4-3{ }^{\circ} \mathrm{C}$ colder, with the coldest temperatures occurring in the northern part of the range. Precipitation during the LGM was predicted to be up to $50 \%$ greater than at present in California, but 10-20\% lower in Baja California. The resulting HOL MAXENT projection predicted a broader, more continuous distribution than the current range, especially in the north (Fig. 1D). In contrast, the LGM MAXENT projection (21 ka) predicted a more narrow distribution and southward shift in the northern range limit of the species, excluding it from the San Bernardino Mountains (Fig. 1E). The stability map (Fig 1F) revealed one large stable area that includes most of the species' range in southern California (hereafter, the northern refugium), and a much smaller, disjunct stable area in the Sierra San Pedro Mártir of northern Baja California (the southern refugium). In sum, these models predict genetic divergence between separate refugia in the north and south of the species range, and relatively low genetic divergence among populations in California within the northern refugium, reflecting greater opportunity for connectivity during the Holocene.

\section{Microsatellite diversity and HWE}

Descriptive statistics for the microsatellites are provided in Table S3 (Supporting information). None of the exact tests for deviations from HWE were significant after correction for multiple comparisons. Microsatellite polymorphism was high: the average number of alleles per locus across all samples was 20 (range $=13-33$ ). Several samples showed group-specific allelic dropout for at least one locus, suggesting mutations in flanking regions and resulting in null alleles. This resulted in a high proportion $(-25 \%)$ of double missing genotypes in each of four loci (ENS4, ENS11, ENS13, ENS15). Global $F_{\mathrm{ST}}$ calculated across all loci using the method of Weir (1996) was not significantly different when using the null allele correction method of Chapuis \& Estoup (2007) vs. not [both methods, $F_{\mathrm{ST}}=0.10 ; 95 \% \mathrm{CI}$ $(0.08,0.13)]$. Allelic differentiation among the 14 samples was highly significant (Fisher's method; $P<0.001$ ), allowing us to reject the null hypothesis that alleles are drawn from the same distribution in all samples.

\section{Population genetic structure}

Structure analysis. Under the no-admixture ancestry model and with allele frequencies modelled as correlated, the mean log probability of the data was greatest for $K=7$. The $\Delta K$ statistic was greatest from 1 to 2 clusters, with little explanatory power gained by adding additional clusters (Fig. 2A). Individuals were assigned to two clusters, separating the San Quintín sample from the remaining individuals. When the San Quintín sample was removed to look for further substructure and the data were reanalysed, the probability of the data increased with the successive addition of clusters to a maximum of $K=6$, after which it gradually decreased (Fig. 2B). The rate of change in the log probability of the data $(\Delta K)$ was greatest from 1 to 2 clusters, though a change of nearly the same magnitude was observed from 10 to 11 clusters. At $K=2$, individuals were divided into one cluster consisting mainly of the Cuyamaca samples and another of the remaining individuals (Fig. 2B). At $K=11$, individuals were further subdivided, but individuals were strongly assigned in only about half of the clusters (Fig. S7, Supporting information).

Geneland analysis. Using the spatial model, assuming no-admixture and correlated allele frequencies, the highest mean posterior density was obtained for $K=11$ (five replicates) or $K=12$ (5 replicates; Fig. 2C). Posterior probabilities of population memberships were equal to one across replicate runs. Individuals usually clustered exactly according to sample group (Fig. 2C).

\section{$I B D$ and IBR as predictors of observed differentiation between sampled populations}

To test the hypothesis that climate-induced habitat shifts have shaped patterns of population persistence and connectivity, we tested whether our stability surface 
A With San Quintín
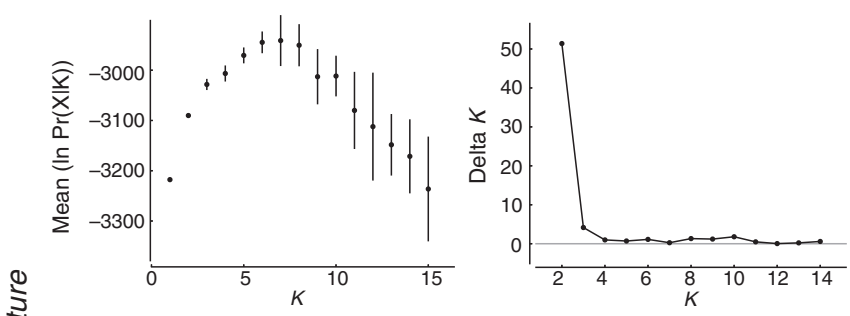

B Without San Quintín
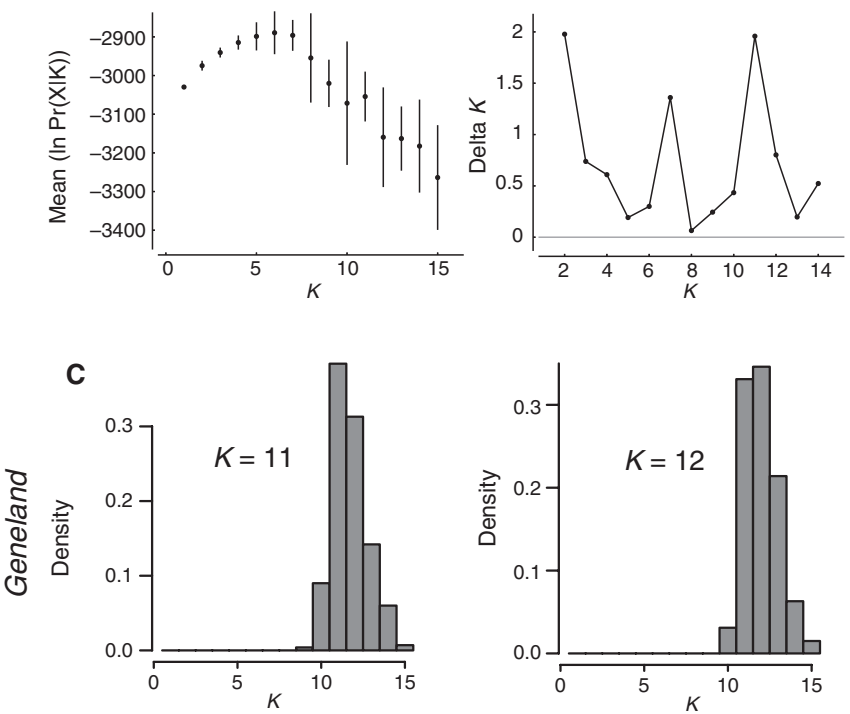

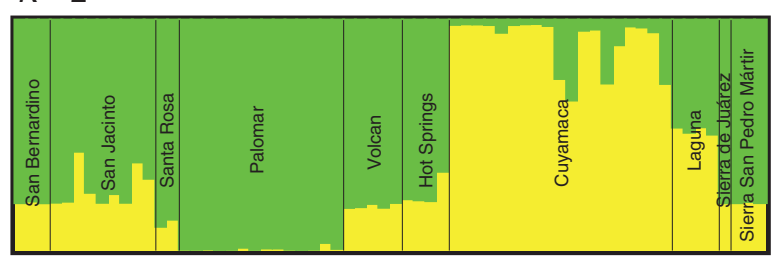

$K=2$

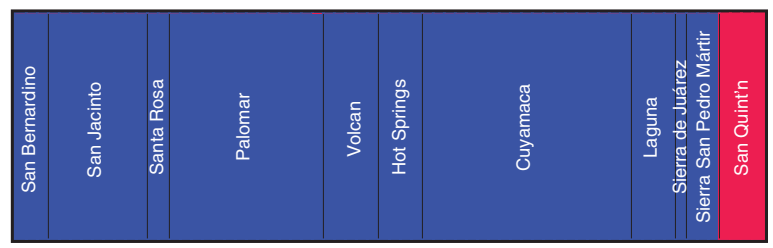

$K=2$

$K=11$

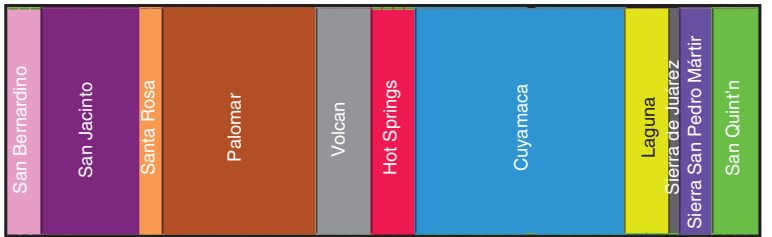

Fig. 2 Results from STRUCTURE and GENELAND analyses under a model of no-admixture and correlated allele frequencies. For STRUCTURE, results are shown for analyses with (A) and without (B) the divergent San Quintin population. Plots show the mean log probability of the data $(\ln \operatorname{Pr}(X \mid K))$ over 10 runs for each value of $K$ from 1 to 15 and the $\Delta K$ statistic (Evanno et al. 2005). For GENELAND, the modal number of clusters was $K=11$ (five replicates) or $K=12$ (five replicates). Each vertical bar in the colored histograms represents the posterior probability that an individual is from a given cluster.

(Fig. 1F) could predict observed patterns of gene flow between pairs of populations better than traditional models of IBD. We performed this analysis using an IBR model to incorporate the effect of spatial heterogeneity present in the stability surface, and then compared this model to traditional IBD gene flow models. When there is IBD among continuous populations, genetic differentiation is expected to increase linearly with geographical distance in one-dimensional habitats, or with the logarithm of geographical distance in two-dimensional habitats (Rousset 1997). We found a positive relationship between linearized $F_{\mathrm{ST}}$ and distance assuming either one or two-dimensional habitats using both Rousset's (1997) original estimator (Table 1; Fig. S8, Supporting information) and its variant (Table 1; Fig. 3). Results were generally congruent between $1 \mathrm{D}$ and 2D models with the original estimator, though a $2 \mathrm{D}$ model provided a slightly better fit when using the modified estimator (Table 1; Fig. 3). The IBR model, however, provided a better fit over IBD models using either the original estimator or its variant, indicating that incorporating spatial heterogeneity in the form of historical habitat stability improved predictions of observed differentiation between sampled populations (Table 1; Fig. 3).

\section{mtDNA phylogeography}

There were 27 unique mtDNA haplotypes among the 64 ingroup individuals sequenced. Average maximumlikelihood corrected pairwise sequence divergence among ingroup haplotypes was $1.3 \%$, with a maximum of $5.4 \%$. Average sequence divergence between E. e. klauberi and the outgroup E. e. croceater was $8.3 \%$. The deepest division in the tree separates the ancestor of the Sierra San Pedro Mártir sample from the ancestor of remaining individuals (Fig. 4). These samples are $\sim 4 \%$ divergence from other ingroup samples. The next division separates two of three individuals from the San Bernardino Mountains at the northern limit of the range, though this relationship is not well supported if 
Table 1 RMA regression results for one-dimensional (1D) and two-dimensional (2D) models of isolation by distance (IBD) and isolation by resistance (IBR) using the regression method of Rousset (1997)

\begin{tabular}{|c|c|c|c|c|}
\hline \multirow[b]{3}{*}{ Model } & \multicolumn{4}{|c|}{ Genetic distance estimator } \\
\hline & \multicolumn{2}{|c|}{$F_{\mathrm{ST}} /\left(1-F_{\mathrm{ST}}\right)$} & \multicolumn{2}{|c|}{$F_{\mathrm{ST}} /\left(1-F_{\mathrm{ST}}\right) *$} \\
\hline & $R^{2}$ & $P$ & $R^{2}$ & $P$ \\
\hline 1D IBD & 0.188 & 0.049 & 0.253 & 0.026 \\
\hline 2D IBD & 0.166 & 0.026 & 0.319 & 0.010 \\
\hline IBR & 0.620 & 0.014 & 0.482 & 0.009 \\
\hline
\end{tabular}

Two estimators of genetic distance were used, the original $F_{\mathrm{ST}} /$ $\left(1-F_{\mathrm{ST}}\right)$, and $F_{\mathrm{ST}} /\left(1-F_{\mathrm{ST}}\right) *$, a minor variant analogous to Rousset's (2000) individual-based estimator. Table entries are $R^{2}$ values for matrix correlation and one-tailed $P$-values. The IBR model was a better predictor of gene flow than either $1 D$ or $2 D$ IBD in both cases. Regressions are shown in Fig. 3 for $F_{\mathrm{ST}} /$ $\left(1-F_{\mathrm{ST}}\right) *$ and in Fig. S8 (Supporting information) for $F_{\mathrm{ST}} /$ $\left(1-F_{\mathrm{ST}}\right)$.

a strict $95 \%$ cut-off is used (posterior probability $=0.91$ ). The remaining sample from the northern San Bernardino Mountains grouped with individuals from the San Jacinto Mountains to the south. A third clade comprises the individuals from the San Quintín population in Baja California, all of which share a single haplotype. The remaining samples form a clade that extends from the San Jacinto and San Bernardino Mountains in the north to the Sierra de Juárez in northern Baja California in the south. Haplotypes generally grouped according to sampling location within this clade; however, relationships among sampled groups were not well supported.

\section{Discussion}

The Transverse and Peninsular Ranges of southern California are considered evolutionary hotspots - areas characterized by rapid diversification and a high concentration of historically isolated lineages (Davis et al. 2007; Vandergast et al. 2008). This extraordinary diversity is thought to result from a combination of several evolutionary and ecological drivers of diversification, including steep environmental gradients, ample opportunities for species interactions, and recent climatic change (Calsbeek et al. 2003; Lapointe \& Rissler 2005; Davis et al. 2007). The aim of this study was to explicitly test how the last of these hypothesized drivers late Quaternary climate-induced range shifts and fragmentation - has influenced patterns of population persistence and connectivity using a montane, dispersal-limited salamander as a test case. Based on our SDM, we expected to see a pattern of high connectivity among populations within the northern refugium and, conversely, a pattern of isolation due to long-term persistence of the Sierra San Pedro Mártir population. Consistent with these expectations, historical measures of population connectivity predicted observed measures of gene flow. MtDNA divergence is low within the northern refugium reflecting greater opportunity for connectivity during the Holocene, but relatively high between separate northern and southern refugia, reflecting isolation and persistence of the Sierra San Pedro Mártir population.

\section{Species range dynamics}

Our model for current climatic conditions performed well over the core, continuous portion of the species range in southern California, but the San Quintín population in Baja California was not predicted. This population (representing the southernmost limit of the species' range) is peripheral both geographically and environmentally and may be restricted to a highly localized microhabitat not well captured by our climate predictors. Habitat in San Quintín consists of a treeless, rocky area surrounded by maritime desert scrub, in contrast to the mid- to high-elevation mixed-conifer forest inhabited by all other known populations.

In contrast to the current isolation of populations, our HOL model predicted this species was more widespread when climatic conditions were slightly warmer and more mesic (Minnich 2007a), particularly in northern Baja California. In contrast, the predicted range is much smaller under the LGM model. This result is somewhat counterintuitive considering that mixed-conifer forests in southern California are thought to have moved downslope by at least $900 \mathrm{~m}$ during the late Pleistocene (Anderson et al. 2002). We hypothesize that the contracted LGM range is a result of conditions being too cold in the northern portion of the range (San Bernardino Mountains) and too dry in the southern portion of the range during the late Pleistocene relative to current conditions. The species is not predicted to have occurred in the San Bernardino Mountains at this time, where the southwestern-most limit of Western Cordillera glaciation occurred (Owen et al. 2003).

It is important to keep in mind the assumptions underlying SDM in interpreting our results. For example, predicted refugia are hypothetical only; when dispersal is limited, some refugia may have been inaccessible to a species (Araújo \& Pearson 2005). Additionally, when distribution models developed for present climatic conditions are projected to time periods where conditions existed that do not currently (so called nonanalogue conditions), results may be misleading (Pearson et al. 2006). Finally, these models assume that climatic limits of a species are stable through time and 

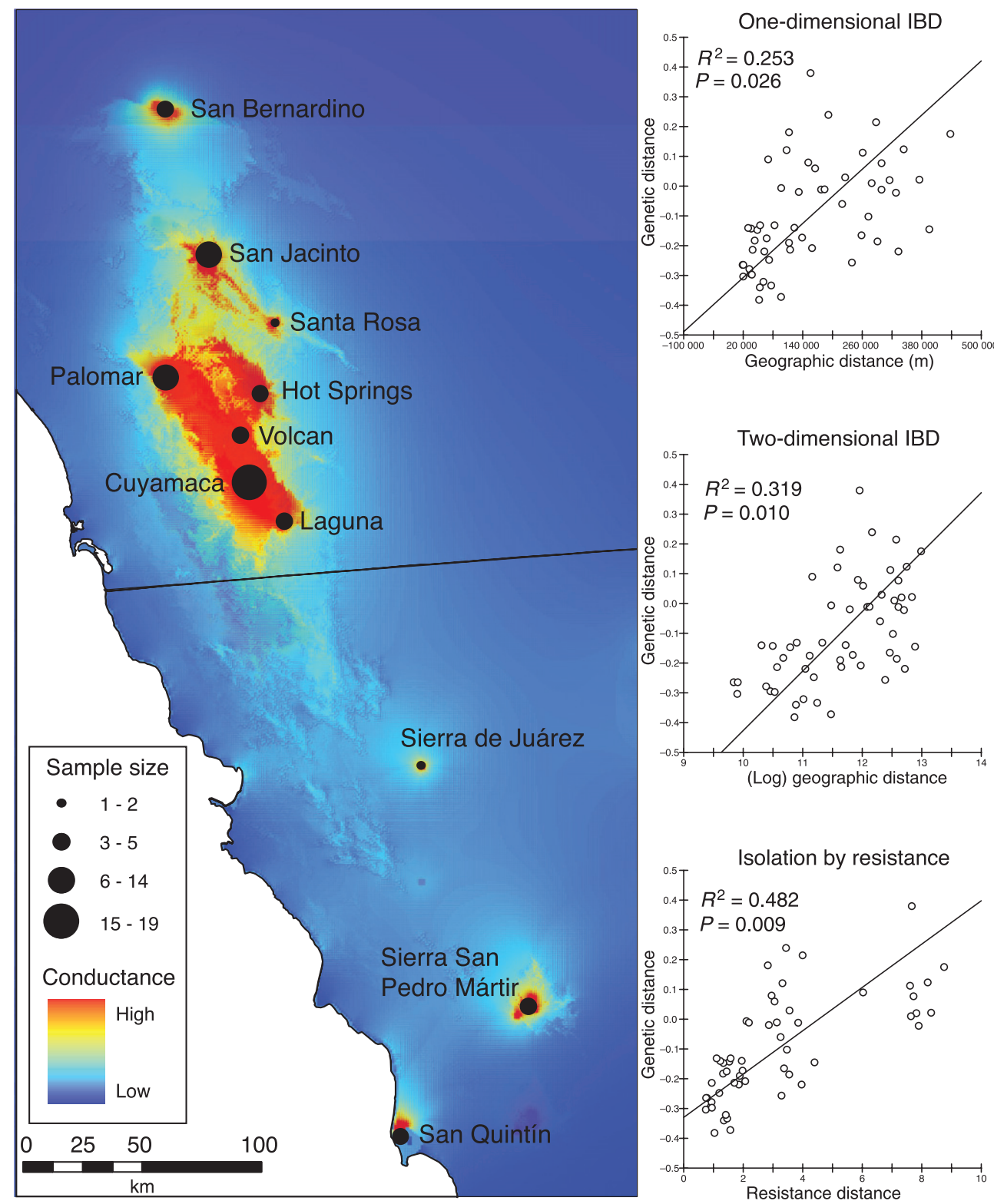

Fig. 3 Range map showing the conductance grid from CIRCUITSCAPE analysis showing populations used to estimate gene flow. Plots are RMA regressions of a variant of Rousset's (1997) $\mathrm{F}_{\mathrm{ST}} /\left(1-F_{\mathrm{ST}}\right)$ estimator against Euclidean distance (one-dimensional IBD), the log of Euclidean distance (two-dimensional IBD), and resistance distance (IBR). Regression plots using Rousset's (1997) original estimator are provided in the Fig. S8 (Supporting information). The IBR model performed better than one- and two-dimensional models of IBD in all cases.

that species' ranges are limited solely by the abiotic environment (Nogués-Bravo 2009).

\section{Population genetic considerations}

Like many species with limited dispersal, the genetic population structure of E. e. klauberi is characterized by a pattern of IBD (i.e. a positive correlation between genetic and geographical distances). The analysis of data from natural populations usually involves uncontrolled factors and simplifying model assumptions, and IBD can be a confounding factor for population genetic inference (Guillot et al. 2009; Meirmans 2012). In particular, IBD may cause the number of clusters $(K)$ to be overestimated when using clustering methods, regardless of the inclusion of spatial information as a prior (Frantz et al. 2009; Guillot et al. 2009; Schwartz \& McKelvey 2009). Although it can be difficult to distinguish between real and artificial genetic clusters when there is IBD (Frantz et al. 2009; Guillot et al. 2009), we do not have any reason to suspect 


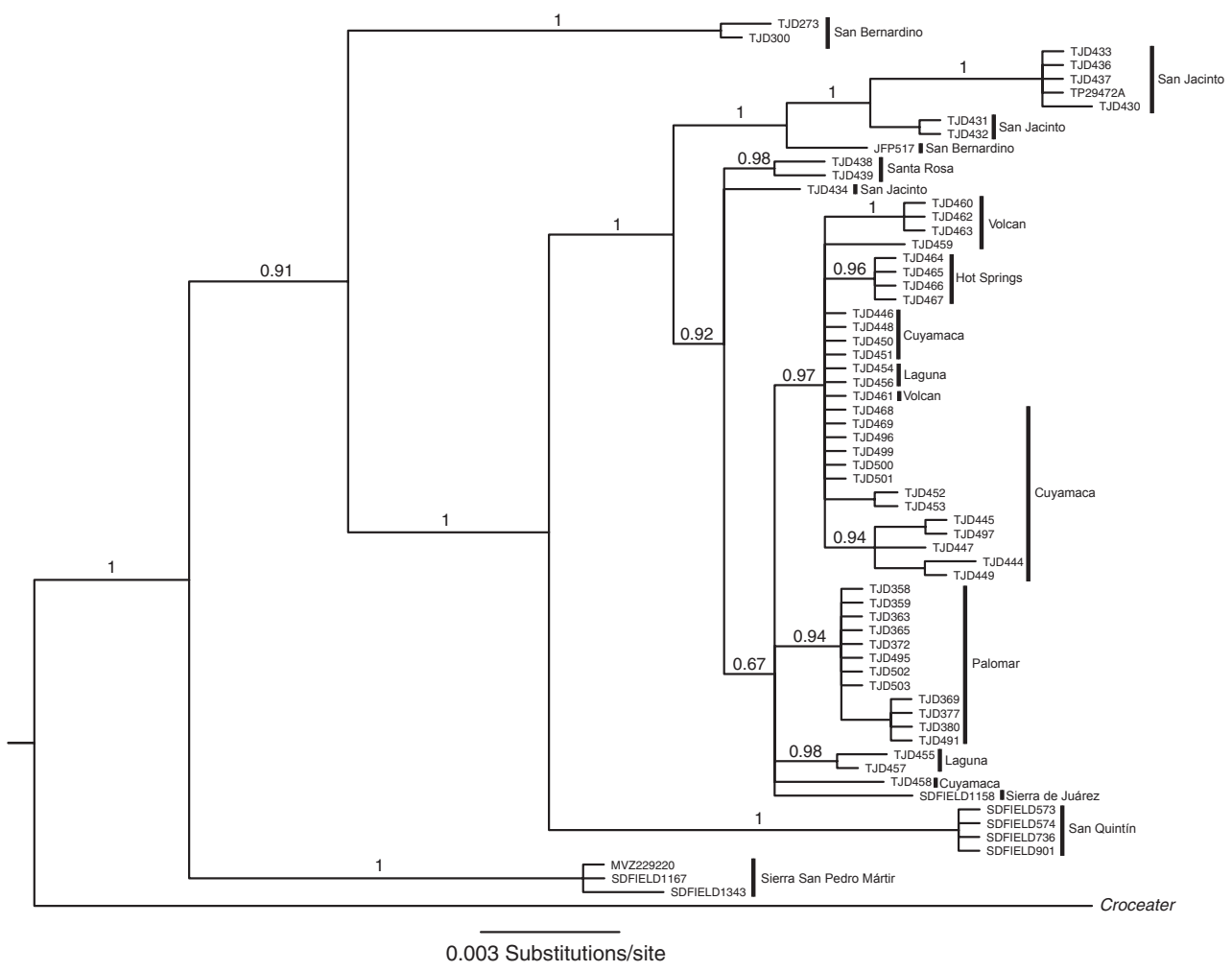

Fig. 4 Phylogenetic relationships based on the 50\% majority rule consensus tree from Bayesian analysis of mtDNA. Numbers on branches represent Bayesian posterior probability values. Specific locality information is provided in Table S1 (Supporting information).

that any of our inferred clusters are artificial, as they conform to HWE expectations and are significantly different based on exact $\mathrm{G}$ tests of population differentiation. Our results are consistent with other studies suggesting that spatial clustering models may provide more accurate estimates of $K$ over nonspatial models when genetic differentiation is low (Guillot et al. 2005a, 2009; Frantz et al. 2006; Fontaine et al. 2007) and underscore the importance of comparing results from multiple programmes because clustering algorithms are heavily influenced by model choice and priors (Guillot et al. 2009).

Although there has been debate about the utility and suitability of $F_{\mathrm{ST}}$ because of its dependency on the level of within-population genetic variation (Meirmans 2006; Meirmans \& Hedrick 2011), particularly for microsatellites (Balloux et al. 2000), Weir \& Cockerham's (1984) $F_{\mathrm{ST}}$ is often appropriate because it is unbiased with respect to sample size. The regression method of Rousset (1997, 2000) which makes use of this estimator has been shown to be robust to mutational and sampling factors (Leblois et al. 2003) as well as spatial and temporal demographic fluctuations (Leblois et al. 2004). This species experiences strong demographic fluctuations in space and time, making even sampling among sites difficult and resulting in small sample sizes for some populations, especially at the limits of the species' range (e.g., in the San Bernardino Mountains, Sierra de Juárez, Sierra San Pedro Mártir, and San Quintín). When small per-group samples are considered, the $F_{\mathrm{ST}} /\left(1-F_{\mathrm{ST}}\right)$ variant which uses a single estimate of within-deme gene diversity (rather than a per-pair estimate) should in principle perform better than the original method (Rousset 2012). Limited testing found little effect of the choice of estimator (Rousset 2012); however, results presented here suggest that using the modified statistic may provide a better fit to the data (Table 1). Further testing is needed to determine the generality of this result.

Despite the seemingly one-dimensional, linear distribution of this species, incorporating spatial heterogeneity using a resistance surface improved predictions of gene flow over traditional IBD methods, as has been shown in previous studies (McRae 2006; McRae \& Beier 2007). The use of resistance surfaces in spatial genetics continues to gain increased popularity, but requires careful consideration for parameterization and analysis (Spear et al. 2010; Koen et al. 2012). In combination with new likelihood-based methods for population genetic inference under IBD (Rousset \& Leblois 2007, 2012), resistance surfaces offer great promise for the analysis of spatial genetic data. 
Comparison with other phylogeographical investigations

The role of late Quaternary climate change in driving patterns of phylogeographical structure has been implicated for a number of terrestrial vertebrates that are codistributed with E. e. klauberi in the southern portion of their ranges (Rodriguez-Robles et al. 1999, 2001; Maldonado et al. 2001; Matocq 2002; Feldman \& Spicer 2006; Spellman et al. 2007; Schoville et al. 2011). Similar to the pattern we observed, mtDNA haplotypes are often shared between populations in the San Bernardino and San Jacinto Mountains (Barrowclough et al. 1999; Maldonado et al. 2001; Schoville et al. 2011), suggesting a relatively recent connection between these ranges. More rapidly evolving microsatellite markers indicate significant population divergence between San Bernardino and San Jacinto mountain isolates in at least one other dispersal-limited amphibian, the mountain yellow-legged frog (Schoville et al. 2011). In the few taxa that extend into northern Baja California, Sierra San Pedro Mártir populations are divergent from southern California populations (Rodriguez-Robles et al. 1999; Maldonado et al. 2001), similar to the pattern observed in E. e. klauberi.

\section{Conclusions and conservation implications}

While our genetic data are consistent with population connectivity across the central core of the range during the Holocene, under the current climate this species is characterized by isolated montane subpopulations with little potential for gene flow. Given projected humaninduced climate change scenarios, habitat fragmentation and local extinction are expected to become increasingly more common, especially in species with limited dispersal ability and restricted, high-elevation distributions (Walther et al. 2002; Thomas et al. 2004; Ohlemüller et al. 2008; Urban et al. 2012). Ecological niche modelling under a general circulation model that assumes a doubling of atmospheric carbon dioxide predicts a dramatic contraction in the range of this species (Devitt et al. unpublished). More immediate threats include habitat loss resulting from development, fires, agriculture, and logging (Stephenson \& Calcarone 1999; Minnich \& Franco-Vizcaíno 2005; Rochester et al. 2010). In California, much of the range of this species occurs in areas that have been identified as hotspots of genetic divergence and diversity, many of which are located outside of protected areas (Davis et al. 2007; Vandergast et al. 2008). In Baja California, populations in the Sierra de Juárez and Sierra San Pedro Mártir are found in relatively intact ecosystems within the borders of national parks, but the only known coastal population is vulnerable to habitat loss given its proximity to the rapidly developing city of San Quintín. Although the sample size for this population is low, multilocus estimates of population differentiation suggest it is highly divergent. Further survey work is needed to determine the extent of this population and whether it warrants protection. Species whose distributions span the international border between the U.S. and Mexico present an additional challenge for conservation, but the evolutionary potential of this unique ecoregion deserves special attention (White et al. 2006; Davis et al. 2007; Vandergast et al. 2008).

\section{Acknowledgements}

We thank David B. Wake, George K. Roderick and five anonymous reviewers for comments on earlier drafts of this manuscript. We thank Gilles Guillot and François Rousset for advice and discussion about analytical methods. For donating samples or assistance in the field, we thank Chuck Brown, Dave Goodward, Megan Lahti, Clark Mahrdt, Ted Papenfuss, Anny Peralta-Garcia, Jim Parham, Greg Pauly, Angelo Soto-Centeno and Jorge Valdez-Villavicencio. For access to collections at UABC, we thank Gorgonio Ruiz-Campos and Jorge Valdez-Villavicencio. Research in Baja California was conducted in collaboration with Exequiel Ezcurra (SEMARNAT 7528). Funding was provided by a Howie Wier Conservation Award from the AnzaBorrego Institute, a University of California Natural Reserve System (UCNRS) Mildred E. Mathias graduate student research grant, the Museum of Vertebrate Zoology Martens and Louise Kellogg funds, the San Diego Natural History Museum (SDNHM), the University of California Institute for Mexico and the United States (UC MEXUS), and the National Science Foundation (DEB-0909821 and DEB-0641078). We thank the ESRI Conservation Program for providing ArcGIS software for our use.

\section{References}

Alberto F (2009) MsatAllele_1.0: an R package to visualize the binning of microsatellite alleles. Journal of Heredity, 100, 394 397.

Allouche O, Tsoar A, Kadmon R (2006) Assessing the accuracy of species distribution models: prevalence, kappa and the true skill statistic (TSS). Journal of Applied Ecology, 43, 1223-1232.

Anderson RS, Power MJ, Smith SJ, Springer K, Scott E (2002) Paleoecology of a Middle Wisconsin Deposit from Southern California. Quaternary Research, 58, 310-317.

Araújo MB, Pearson RG (2005) Equilibrium of species' distributions with climate. Ecography, 28, 693-695.

Arévalo E, Davis SK, Sites JW Jr (1994) Mitochondrial DNA sequence divergence and phylogenetic relationships among eight chromosome races of the Sceloporus grammicus complex (Phrynosomatidae) in central Mexico. Systematic Biology, 43, 387-418.

Balloux F, Brunner H, Lugon-Moulin N, Hausser J, Goudet J (2000) Microsatellites can be misleading: an empirical and simulation study. Evolution, 54, 1414-1422. 
Barrowclough GF, Gutierrez RJ, Groth JG (1999) Phylogeography of Spotted Owl (Strix occidentalis) populations based on mitochondrial DNA sequences: gene flow, genetic structure, and a novel biogeographic pattern. Evolution, 53, 919-931.

Barve N, Barve V, Jiménez-Valverde A et al. (2011) The crucial role of the accessible area in ecological niche modeling and species distribution modeling. Ecological Modelling, 222, 1810-1819.

Bell RC, Parra JL, Tonione M et al. (2010) Patterns of persistence and isolation indicate resilience to climate change in montane rainforest lizards. Molecular Ecology, 19, 25312544.

Braconnot P, Otto-Bliesner B, Harrison S et al. (2007) Results of PMIP2 coupled simulations of the Mid-Holocene and last glacial maximum - Part 1: experiments and large-scale features. Climate of the Past, 3, 261-277.

Brandley MC, Schmitz A, Reeder TW (2005) Partitioned Bayesian analyses, partition choice, and the phylogenetic relationships of scincid lizards. Systematic Biology, 54, 373-390.

Calsbeek R, Thompson JN, Richardson JE (2003) Patterns of molecular evolution and diversification in a biodiversity hotspot: the California Floristic Province. Molecular Ecology, 12, 1021-1029.

Carnaval AC, Hickerson MJ, Haddad CFB, Rodrigues MT, Moritz C (2009) Stability predicts genetic diversity in the Brazilian Atlantic forest hotspot. Science, 323, 785-789.

Carstens BC, Richards CL (2007) Integrating coalescent and ecological niche modeling in comparative phylogeography. Evolution, 61, 1439-1454.

Carvajal-Rodriguez A, de Uña-Alvarez J (2011) Assessing significance in high-throughput experiments by sequential goodness of fit and $q$-Value estimation. PLoS One, 6, e24700.

Chapuis M-P, Estoup A (2007) Microsatellite null alleles and estimation of population differentiation. Molecular Biology and Evolution, 24, 621-631.

Crandall KA, Bininda-Emonds ORP, Mace GM, Wayne RK (2000) Considering evolutionary processes in conservation biology. Trends in Ecology \& Evolution, 15, 290-295.

Davic RD, Welsh HH Jr (2004) On the ecological roles of salamanders. Annual Review of Ecology and Systematics, 35, 405-434.

Davis EB, Koo MS, Conroy C, Patton JL, Moritz C (2008) The California hotspots project: identifying regions of rapid diversification of mammals. Molecular Ecology, 17, 120-138.

Dempster AP, Laird NM, Rubin DB (1977) Maximum likelihood from incomplete data via the EM algorithm. Journal of the Royal Statistical Society. Series B (Methodological), 39, 1-38.

Devitt TJ, Cameron Devitt SE, Hollingsworth BD, McGuire JA, Moritz C (2013) Data from: Montane refugia predict population genetic structure in the Large-blotched Ensatina Salamander. Dryad Data Repository. doi:10.5061/dryad.k9 g50

Devitt TJ, Pereira R, Jakkula L et al. (2009) Isolation and characterization of 15 polymorphic microsatellites in the Plethodontid salamander Ensatina eschscholtzii. Molecular Ecology Resources, 9, 966-969.

D'Horta FM, Cabanne GS, Meyer D, Miyaki CY (2011) The genetic effects of late quaternary climatic changes over a tropical latitudinal gradient: diversification of an Atlantic Forest passerine. Molecular Ecology, 20, 1923-1935.

Geneious version 4.8 .5 created by Biomatters. Available from http://www.geneious.com/.
Evanno G, Regnaut S, Goudet J (2005) Detecting the number of clusters of individuals using the software STRUCTURE: a simulation study. Molecular Ecology, 14, 2611-2620.

Falush D, Stephens M, Pritchard JK (2003) Inference of population structure using multilocus genotype data: linked loci and correlated allele frequencies. Genetics, 164, 1567-1587.

Falush D, Stephens M, Pritchard JK (2007) Inference of population structure using multilocus genotype data: dominant markers and null alleles. Molecular Ecology Notes, 7, 574-578.

Feder ME (1983) Integrating the ecology and physiology of plethodontid salamanders. Herpetologica, 39, 291-310.

Feldman CR, Spicer GS (2006) Comparative phylogeography of woodland reptiles in California: repeated patterns of cladogenesis and population expansion. Molecular Ecology, 15, 2201-2222.

Fielding AH, Bell JF (1997) A review of methods for the assessment of prediction errors in conservation presence/absence models. Environmental Conservation, 24, 38-49.

Fontaine M, Baird S, Piry S et al. (2007) Rise of oceanographic barriers in continuous populations of a cetacean: the genetic structure of harbour porpoises in Old World waters. BMC Biology, 5, 30.

Frantz AC, Pourtois JT, Heuertz M et al. (2006) Genetic structure and assignment tests demonstrate illegal translocation of red deer (Cervus elaphus) into a continuous population. Molecular Ecology, 15, 3191-3203.

Frantz AC, Cellina S, Krier A, Schley L, Burke T (2009) Using spatial Bayesian methods to determine the genetic structure of a continuously distributed population: clusters or isolation by distance? Journal of Applied Ecology, 46, 493-505.

Freeman EA, Moisen GG (2008) A comparison of the performance of threshold criteria for binary classification in terms of predicted prevalence and kappa. Ecological Modelling, 217, $48-58$.

Goudet J, Raymond M, de-Meeus T, Rousset F (1996) Testing differentiation in diploid populations. Genetics, 144, 1933-1940.

Green DM, Sharbel TF, Kearsley J, Kaiser H (1996) Postglacial range fluctuation, genetic subdivision and speciation in the Western North American Spotted Frog complex, Rana pretiosa. Evolution, 50, 374-390.

Guillot G (2008) Inference of structure in subdivided populations at low levels of genetic differentiation - the correlated allele frequencies model revisited. Bioinformatics, 24, 2222-2228.

Guillot G, Santos F (2009) A computer program to simulate multilocus genotype data with spatially autocorrelated allele frequencies. Molecular Ecology Resources, 9, 1112-1120.

Guillot G, Estoup A, Mortier F, Cosson JF (2005a) A spatial statistical model for landscape genetics. Genetics, 170, 1261-1280.

Guillot G, Mortier F, Estoup A (2005b) GENELAND: a computer package for landscape genetics. Molecular Ecology Notes, 5, 712-715.

Guillot G, Santos F, Estoup A (2008) Analysing georeferenced population genetics data with Geneland: a new algorithm to deal with null alleles and a friendly graphical user interface. Bioinformatics, 24, 1406-1407.

Guillot G, Leblois R, Coulon A, Frantz AC (2009) Statistical methods in spatial genetics. Molecular Ecology, 18, 4734-4756. 
Guo S, Thompson E (1992) Performing the exact test of Hardy-Weinberg proportion for multiple alleles. Biometrics, 48, 361-372.

Haldane JBS (1954) An exact test for randomness of mating. Journal of Genetics, 52, 631-635.

Heim CD, Alexander B, Hansen RW et al. (2005) Geographic distribution: Ensatina eschscholtzii klauberi. Herpetological Review, 36, 330-331.

Hellberg ME (1994) Relationships between inferred levels of gene flow and geographic distance in a Philopatric Coral, Balanophyllia elegans. Evolution, 48, 1829-1854.

Hewitt GM (1996) Some genetic consequences of ice ages, and their role in divergence and speciation. Biological Journal of the Linnean Society, 58, 247-276.

Hewitt GM (2000) The genetic legacy of the Quaternary ice ages. Nature, 405, 907-913.

Hewitt GM (2004) Genetic consequences of climatic oscillations in the Quaternary. Philosophical Transactions of the Royal Society of London Series B-Biological Sciences, 359, 183-195.

Hijmans RJ, Cameron SE, Parra JL, Jones PG, Jarvis A (2005) Very high resolution interpolated climate surfaces for global land areas. International Journal of Climatology, 25, 1965-1978.

Hubisz MJ, Falush D, Stephens M, Pritchard JK (2009) Inferring weak population structure with the assistance of sample group information. Molecular Ecology Resources, 9, 1322-1332.

Huelsenbeck JP, Ronquist F (2001) MRBAYES: Bayesian inference of phylogenetic trees. Bioinformatics, 17, 754-755.

Jackman TR, Wake DB (1994) Evolutionary and historical analysis of protein variation in the blotched forms of salamanders of the Ensatina complex (Amphibia: Plethodontidae). Evolution, 48, 876-897.

Jensen J, Bohonak A, Kelley S (2005) Isolation by distance, web service. BMC Genetics, 6, 13.

Johnson CM, Johnson LB, Richards C, Beasley V (2002) Predicting the occurrence of amphibians: an assessment of multiplescale models. In: Predicting Species Occurrences: Issues of Accuracy and Scale (eds Scott JM, Heglund PJ, Morrison ML et al.), pp. 157-170. Island Press, Washington, DC.

Kalinowski ST (2005) HP-Rare 1.0: a computer program for performing rarefaction on measures of allelic richness. Molecular Ecology Notes, 5, 187-189.

Knowles LL, Carstens BC, Keat ML (2007) Coupling genetic and ecological-niche models to examine how past population distributions contribute to divergence. Current Biology, 17, 940-946.

Koen EL, Bowman J, Walpole AA (2012) The effect of cost surface parameterization on landscape resistance estimates. Molecular Ecology Resources, 12, 686-696.

Kuchta SR, Parks DS, Mueller RL, Wake DB (2009) Closing the ring: historical biogeography of the salamander ring species Ensatina eschscholtzii. Journal of Biogeography, 36, 982-995.

Lanfear R, Calcott B, Ho SYW, Guindon S (2012) PartitionFinder: combined selection of partitioning schemes and substitution models for phylogenetic analyses. Molecular Biology and Evolution, 29, 1695-1701.

Lapointe F-J, Rissler LJ (2005) Congruence, consensus, and the comparative phylogeography of codistributed species in California. The American Naturalist, 166, 290-299.

Lawson LP (2010) The discordance of diversification: evolution in the tropical-montane frogs of the Eastern Arc Mountains of Tanzania. Molecular Ecology, 19, 4046-4060.
Leblois R, Estoup A, Rousset F (2003) Influence of mutational and sampling factors on the estimation of demographic parameters in a "continuous" population under isolation by distance. Molecular Biology and Evolution, 20, 491-502.

Leblois R, Rousset F, Estoup A (2004) Influence of spatial and temporal heterogeneities on the estimation of demographic parameters in a continuous population using individual microsatellite data. Genetics, 166, 1081-1092.

Lessa EP, Cook JA, Patton JL (2003) Genetic footprints of demographic expansion in North America, but not Amazonia, during the Late Quaternary. Proceedings of the National Academy of Sciences, 100, 10331-10334.

Levene H (1949) On a matching problem arising in genetics. The Annals of Mathematical Statistics, 20, 91-94.

Mahrdt CR, McPeak RH, Grismer LL (1998) The discovery of Ensatina eschscholtzii klauberi (Plethodontidae) in the Sierra San Pedro Mártir, Baja California, México. Herpetological Natural History, 6, 73-76.

Maldonado JE, Vilá C, Wayne RK (2001) Tripartite genetic subdivisions in the ornate shrew (Sorex ornatus). Molecular Ecology, 10, 127-147.

Mantel N (1967) The detection of disease clustering and a generalized regression approach. Cancer Research, 27, 209-220.

Matocq MD (2002) Phylogeographical structure and regional history of the dusky-footed woodrat, Neotoma fuscipes. Molecular Ecology, 11, 229-242.

McRae BH (2006) Isolation by resistance. Evolution, 60, 1551-1561.

McRae BH, Beier P (2007) Circuit theory predicts gene flow in plant and animal populations. Proceedings of the National Academy of Sciences, 104, 19885-19890.

McRae BH, Shah VB (2009) Circuitscape User Guide. Online. The University of California, Santa Barbara. Available at: http:// www.circuitscape.org.

McRae BH, Dickson BG, Keitt TH, Shah VB (2008) Using circuit theory to model connectivity in ecology, evolution, and conservation. Ecology, 89, 2712-2724.

Meirmans PG (2006) Using the AMOVA framework to estimate a standardized genetic differentiation measure. Evolution, 60, 2399-2402.

Meirmans PG (2012) The trouble with isolation by distance. Molecular Ecology, 21, 2839-2846.

Meirmans PG, Hedrick PW (2011) Assessing population structure: $\mathrm{F}_{\mathrm{ST}}$ and related measures. Molecular Ecology Resources, 11, 5-18.

Minnich RA (1983) Fire mosaics in southern California and northern Baja California. Science, 219, 1287-1294.

Minnich RA (2007a) California climate, paleoclimate and paleovegetation. In: Terrestrial Vegetation of California (eds Barbour MG, Keeler-Wolf T, Schoenherr AA), pp. 43-70. University of California Press, Berkeley, California.

Minnich RA (2007b) Southern California Conifer forests. In: Terrestrial Vegetation of California (eds Barbour M, KeelerWolf T, Schoenherr AA), pp. 502-538. University of California Press, Berkeley, California.

Minnich RA, Franco-Vizcaíno E (2005) Baja California's enduring Mediterranean vegetation: early accounts, human impacts, and conservation status. In: Biodiversity, Ecosystems, and Conservation in Northern Mexico (eds Cartron J-LE, Ceballos G), pp. 370-386. Oxford University Press, New York. 
Moritz C (2002) Strategies to protect biological diversity and the processes that sustain it. Systematic Biology, 51, 238-254.

Moritz C, Schneider C, Wake DB (1992) Evolutionary relationships within the Ensatina eschscholtzii complex confirm the ring species interpretation. Systematic Biology, 41, 273-291.

Nice CC, Shapiro AM (2001) Patterns of morphological, biochemical, and molecular evolution in the Oeneis chryxus complex (Lepidoptera: Satyridae): a test of historical biogeographical hypotheses. Molecular Phylogenetics and Evolution, 20, 111-123.

Nogués-Bravo D (2009) Predicting the past distribution of species climatic niches. Global Ecology and Biogeography, 18, 521-531.

Nylander JAA, Ronquist F, Huelsenbeck JP, Nieves-Aldrey JL (2004) Bayesian phylogenetic analysis of combined data. Systematic Biology, 53, 47-67.

Ohlemüller R, Anderson BJ, Araújo MB et al. (2008) The coincidence of climatic and species rarity: high risk to small-range species from climate change. Biology Letters, 4, 568-572.

Owen LA, Finkel RC, Minnich RA, Perez AE (2003) Extreme southwestern margin of late Quaternary glaciation in North America: timing and controls. Geology, 31, 729-732.

Pearson RG, Thuiller W, Araújo MB et al. (2006) Model-based uncertainty in species range prediction. Journal of Biogeography, 33, 1704-1711.

Phillips SJ, Anderson RP, Schapire RE (2006) Maximum entropy modeling of species geographic distributions. Ecological Modelling, 19, 0.

Pritchard JK, Stephens M, Donnelly P (2000) Inference of population structure using multilocus genotype data. Genetics, 155, 945-959.

Rambaut A, Drummond AJ (2007) Tracer. Available from http://tree.bio.ed.ac.uk/software/tracer/

Rannala B, Zhu T, Yang Z (2012) Tail paradox, partial Identifiability, and Influential priors in Bayesian branch length inference. Molecular Biology and Evolution, 29, 325-335.

Raymond M, Rousset F (1995) GENEPOP (Version 1.2): population genetics software for exact tests and ecumenicism. Journal of Heredity, 86, 248-249.

Rissler LJ, Hijmans RJ, Graham CH, Moritz C, Wake DB (2006) Phylogeographic lineages and species comparisons in conservation analyses: a case study of California herpetofauna. The American Naturalist, 167, 655-666.

Robertson A, Hill WG (1984) Deviations from Hardy-Weinberg proportions: sampling variances and use in estimation of inbreeding coefficients. Genetics, 107, 703-718.

Rochester CJ, Brehme CS, Clark DR et al. (2010) Reptile and amphibian responses to large-scale wildfires in Southern California. Journal of Herpetology, 44, 333-351.

Rodriguez-Robles JA, Denardo DF, Staub RE (1999) Phylogeography of the California mountain kingsnake, Lampropeltis zonata (Colubridae). Molecular Ecology, 8, 1923-1934.

Rodriguez-Robles JA, Stewart GR, Pappenfuss TJ (2001) Mitochondrial DNA-based phylogeography of North American rubber boas, Charina bottae (Serpentes: Boidae). Molecular Phylogenetics and Evolution, 18, 227-237.

Ronquist F, Huelsenbeck J (2003) MrBayes 3: Bayesian phylogenetic inference under mixed models. Bioinformatics, 19, 1572-1574

Rousset F (1997) Genetic differentiation and estimation of gene flow from $F$-statistics under isolation by distance. Genetics, $145,1219-1228$.

Rousset F (2000) Genetic differentiation between individuals. Journal of Evolutionary Biology, 13, 58-62.
Rousset F (2008) genepop'007: a complete re-implementation of the genepop software for Windows and Linux. Molecular Ecology Resources, 8, 103-106.

Rousset F (2012) GENEPOP 4.1.3 for Windows/Linux/Mac OS $X, p$. Documentation for GENEPOP software.

Rousset F, Leblois R (2007) Likelihood and approximate likelihood analyses of genetic Structure in a linear habitat: performance and robustness to model mis-specification. Molecular Biology and Evolution, 24, 2730-2745.

Rousset F, Leblois R (2012) Likelihood-based inferences under Isolation by distance: two-dimensional habitats and confidence intervals. Molecular Biology and Evolution, 29, 957-973.

Rovito SM (2010) Lineage divergence and speciation in the web-toed Salamanders (Plethodontidae: Hydromantes) of the Sierra Nevada, California. Molecular Ecology, 19, 4554- 4571.

Schoville SD, Roderick GK (2009) Alpine biogeography of Parnassian butterflies during Quaternary climate cycles in North America. Molecular Ecology, 18, 3471-3485.

Schoville SD, Tustall TS, Vredenburg VT et al. (2011) Conservation genetics of evolutionary lineages of the endangered mountain yellow-legged frog, Rana muscosa (Amphibia: Ranidae), in southern California. Biological Conservation, 144, 2031-2040.

Schwartz MK, McKelvey KS (2009) Why sampling scheme matters: the effect of sampling scheme on landscape genetic results. Conservation Genetics, 10, 441-452.

Spear SF, Balkenhol N, Fortin M-J, McRae BH, Scribner K (2010) Use of resistance surfaces for landscape genetic studies: considerations for parameterization and analysis. Molecular Ecology, 19, 3576-3591.

Spellman GM, Riddle BR, Klicka J (2007) Phylogeography of the mountain chickadee (Poecile gambeli): diversification, introgression, and expansion in response to Quaternary climate change. Molecular Ecology, 16, 1055-1068.

Staub NL, Brown CW, Wake DB (1995) Patterns of growth and movements in a population of Ensatina eschscholtzii platensis (Caudata: Plethodontidae) in the Sierra Nevada, California. Journal of Herpetology, 29, 593-599.

Stebbins RC (1954) Natural history of the salamanders of the plethodontid genus Ensatina. University of California Publications in Zoology, 54, 47-124.

Stebbins RC (2003) A Field Guide to Western Reptiles and Amphibians, 3rd edn. Houghton Mifflin Company, New York.

Stein BA, Kutner LS, Adams JS (2000) Precious Heritage: The Status of Biodiversity in the United States. Oxford University Press, Oxford, p. 416.

Stephenson JR, Calcarone GM (1999) Southern California mountains and foothills assessment: habitat and species conservation issues. In: General Technical Report GTR-PSW175 , p. 402. Pacific Southwest Research Station, Forest Service, U.S. Department of Agriculture, Albany, California.

Thomas CD, Cameron A, Green RE et al. (2004) Extinction risk from climate change. Nature, 427, 145-148.

Urban MC, Tewksbury JJ, Sheldon KS (2012) On a collision course: competition and dispersal differences create noanalogue communities and cause extinctions during climate change. Proceedings of the Royal Society B: Biological Sciences, 279, 2072-2080.

Vandergast AG, Bohonak AJ, Hathaway SA, Boys J, Fisher RN (2008) Are hotspots of evolutionary potential adequately protected in southern California? Biological Conservation, 141, $1648-1664$. 
Walther G-R, Post E, Convey P et al. (2002) Ecological responses to recent climate change. Nature, 416, 389-395.

Weir BS (1996) Genetic Data Analysis II. Sinauer Associates, Inc., Sunderland, Massachusetts.

Weir BS, Cockerham CC (1984) Estimating F-statistics for the analysis of population structure. Evolution, 38, 1358-1370.

White MD, Stallcup JA, Comer K et al. (2006) Designing and establishing conservation areas in the Baja California-Southern California border region. Report for California Department of Fish and Game. Conservation Biology Institute, Encinitas, California

Wiens JJ (2004) Speciation and ecology revisited: phylogenetic niche conservatism and the origin of species. Evolution, 58, 193-197.

Wright S (1943) Isolation by distance. Genetics, 28, 114-138.

Zhang C, Rannala B, Yang Z (2012) Robustness of compound Dirichlet priors for Bayesian inference of branch lengths. Systematic Biology, 61, 779-784.

T.J.D. designed the study, collected material and genetic data, analyzed and interpreted results, and wrote the manuscript. S.E.C.D. performed the distribution modelling, interpreted results, and provided extensive feedback that improved the manuscript. B.D.H. coordinated fieldwork in Mexico and provided key tissue samples. J.A.M. and C.M. participated in fieldwork and provided significant intellectual contributions that greatly improved the study and final manuscript. All authors read and approved the final manuscript.

\section{Data accessibility}

Microsatellite genotypes, final DNA alignment and all input files needed to recreate the results reported in this article have been deposited in DRYAD (doi:10.5061/ dryad.k9 g50). DNA sequences have been deposited in GenBank (accessions KC209980-KC210044).

\section{Supporting information}

Additional supporting information may be found in the online version of this article.

Fig. S1 SDM for current climatic conditions using the subsampled dataset $(\mathrm{N}=23)$.

Fig. S2 Logistic values averaged across 100 bootstrap replicates indicating high spatial concordance across replicates.

Fig. S3 Median logistic values across 100 bootstrapped runs indicating high spatial concordance across replicates.

Fig. S4 Standard deviation in logistic values across 100 bootstrapped runs indicating high spatial concordance across replicates.

Fig. S5 The values shown here give the absolute difference in predictions when using clamping vs. not using clamping.

Fig. S6 Each response curve indicates how the logistic prediction changes as each bioclim variable is varied, while holding all other variables at their average sample value. 